\title{
Human Behavior Terhadap Objek Arsitektural bagi Anak Autistik
}

\author{
Gabyawan Arioseno dan Collinthia Erwindi \\ Departemen Arsitektur, Fakultas Arsitektur, Desain dan Perencanaan, Institut Teknologi Sepuluh Nopember (ITS) \\ e-mail: c_erwindi@arch.its.ac.id
}

\begin{abstract}
Abstrak-Setiap tahun di seluruh dunia, tingkat autisme mengalami peningkatan. Awal tahun1990-an, kasus autisme masih berkisar pada perbandingan 1 : 2.000 kelahiran. Adapun permasalahan-permasalahan yang timbul saat meningkatnya jumlah anak pengidap autis. Objek rancang yang dibuat bertujuan untuk mewadahi anak pengidap autis yang akan diperbaiki atau dilatih perilakunya sehingga dituntuk anak pengidap autis tidak takut dengan dunia luar. Metodologi yang dipakai untuk menyelesaikan permasalahan anak pengidap autis yaitu dengan cara human behavior dikarenakan untuk merancang diperlukan ilmu dari apa saja perilaku yang tidak disukai oleh anak pengidap autis dan apa saja perilaku yang disukai oleh anak pengidap autis tersebut. Awalnya anak pengidap autis harus diperkenalkan image dunia luar supaya mereka mengenalnya lebih dekat dan tidak cenderung mengucilkan diri. Sehingga objek yang diperuntukkan untuk anak autis dituntut untuk melatih mereka agar mereka tidak lagi mengucilkan diri atau malu terhadap lingkungan sekitarnya.
\end{abstract}

Kata Kunci-Human Behavior, Image, Tingkat Autisme.

\section{PENDAHULUAN}

A UTIS berasal dari kata auto yang berarti sendiri. Penyandang autis seakan-akan hidup di dunianya sendiri.Istilah autisme baru diperkenalkan sejak tahun 1943 oleh Leo Kanner, ahli psikiater anak di John Hopkins University. Autisme adalah gangguan perkembangan yang kompleks, yang disebabkan oleh adanya kerusakan pada otak, sehingga mengakibatkan gangguan pada perkembangan komunikasi, perilaku, kemampuan sosialisasi, sensori dan belajar [1]. Autisme merupakan gangguan perkembangan, gangguan pemahaman atau gangguan pervasif, dan bukan suatu bentuk penyakit mental.

Gangguan autistik, gejala ini sering diartikan orang saat mendengar kata autis. Penyandangnya memiliki masalah interaksi sosial, berkomunikasi, dan permainan imaginasi pada anak di bawah usia lima tahun. Objek rancang ini menghadirkan ruang pribadi untuk mengembangkan bakat dari individu pengidap autis ini karena individu yang pengidap autis itu mempunya kemampuan yang hebat daripada individu dengan tumbuh kembang yang biasa.

Lingkup perancangan ini untuk memaksimalkan pembentukan ruang dalam bangunan dan lingkungan berdasarkan tingkat kenyamanan untuk anak pengidap autis beraktivitas dan tinggal. Jika lingkup perancangan tidak berdasarkan tersebut akan memperparah anak pengidap autis dalam melakukan hal yang tidak semestinya anak normal pada umumnya (Gambar 1). Penentuan wilayah perancangan ini

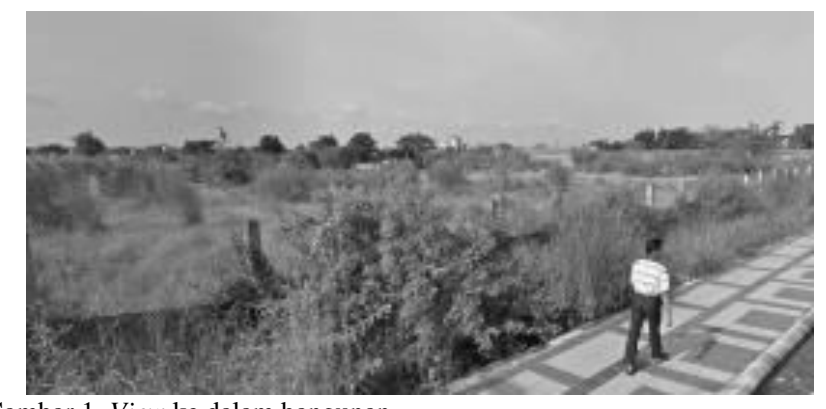

Gambar 1. View ke dalam bangunan.

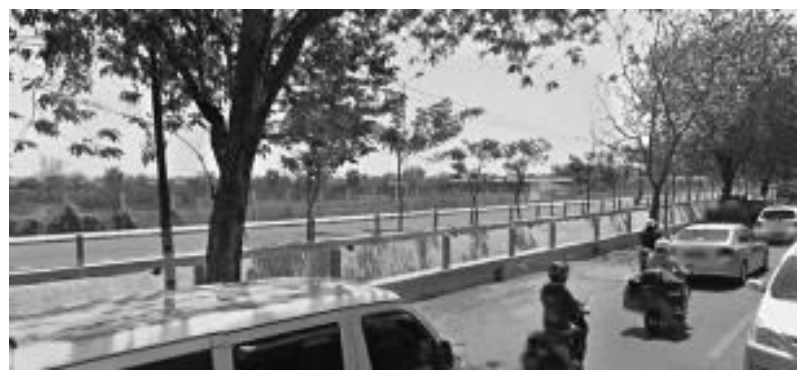

Gambar 2. Tingkat kepadatan sekitar.

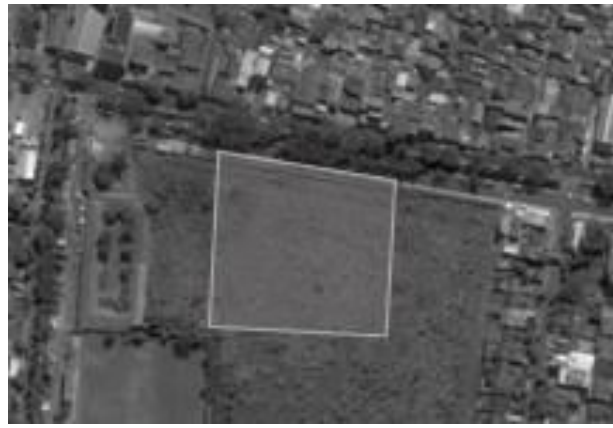

Gambar 3. Lahan rancang.

berada di dekat perumahan-perumahan dikarenakan perumahan pada umumnya beraktivitas yang tidak terlalu aktif sehingga tingkat kebisingan yang dihasilkan oleh perumahan cukup rendah. Penentuan wilayah perancangan cukup tepat untuk meminimalisir kebisingan dari luar yang akan masuk ke objek rancang (Gambar 2).

Pengguna dan pengunjung pada kawasan ini sangat beragam dan dari berbagai lapisan masyarakat. Keberagaman ini terjadi akibat dari berbagai macam fasilitas dan aktivitas yang ada di Jl. Raya Menganti, Surabaya tersebut (Gambar 3). Umumnya masyarakat di wilayah tersebut untuk berobat atau untuk mengenyam pendidikan didukung adanya rumah sakit dan sekolah dasar hingga sekolah menengah atas [2]. 


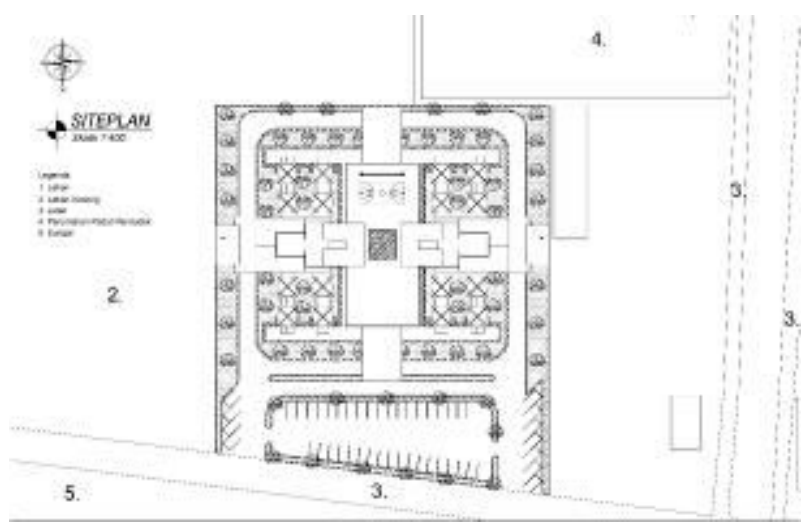

Gambar 4. Site plan.

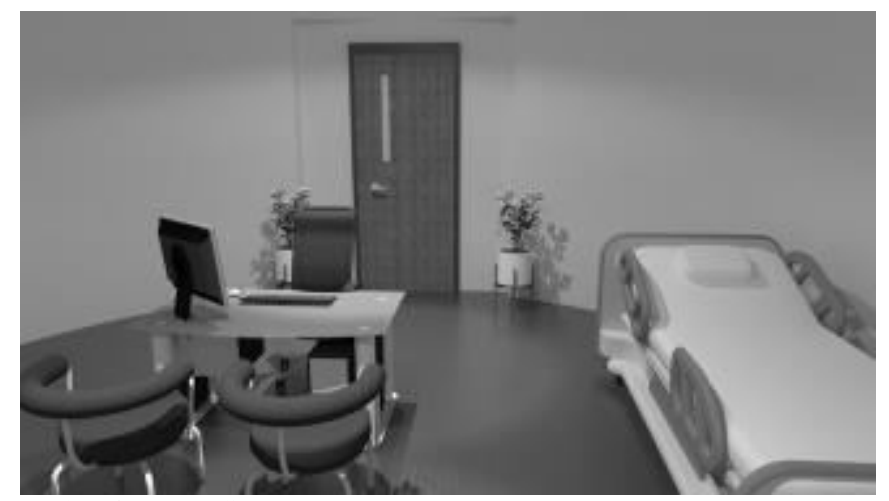

Gambar 5. Ruang diagnose.

Berdasarkan latar belakang, permasalahan yang akan diangkat dalam kasus ini adalah bagaimana cara untuk memperkenalkan dunia luar kepada anak pengidap autis dengan cara non medis (terapi) namun mempikirkan keadaan sekitar sehingga mempengaruhi pembentukan ruang dengan sedemikian rupa supaya anak pengidap autis dapat memahami keadaan dunia luar guna untuk mempersiapkan mereka menghadapi dunia luar (Gambar 4).

\section{METODA PERANCANGAN}

Architectural theory contends that the social behavior of building users is influenced, even determined, by the physical environment in which the behavior occurs [3]. Pendekatan rancang untuk objek ini menggunakan human behavior karena untuk memfokuskan objek rancang menurut perilaku orang yang akan menggunakan objek rancang ini. For Architects, influencing human behavior is doing so for the betterment of the "human condition"; as Sigfried Gideon has argued, their self-assumed goal is "to reinstate basic human values" [4]. Objek rancang ini ingin dirancang untuk mempengaruhi perilaku subjeknya untuk mempersiapkan menghadapi dunia luar sehingga anak pengidap autis ini tidak terganggu dengan munculnya aktivitas yang tidak pernah mereka ketahui di dunia luar.

\section{A. Perception of Space}

Kemampuan dengan cara persepsi ruang ini meliputi kepekaan pada warna, garis, bentuk, ruang, dan hubungan antar unsur tersebut dan kemampuan ini dapat membayangkan dan mempresentasikan ide secara visual atau spasial, dan

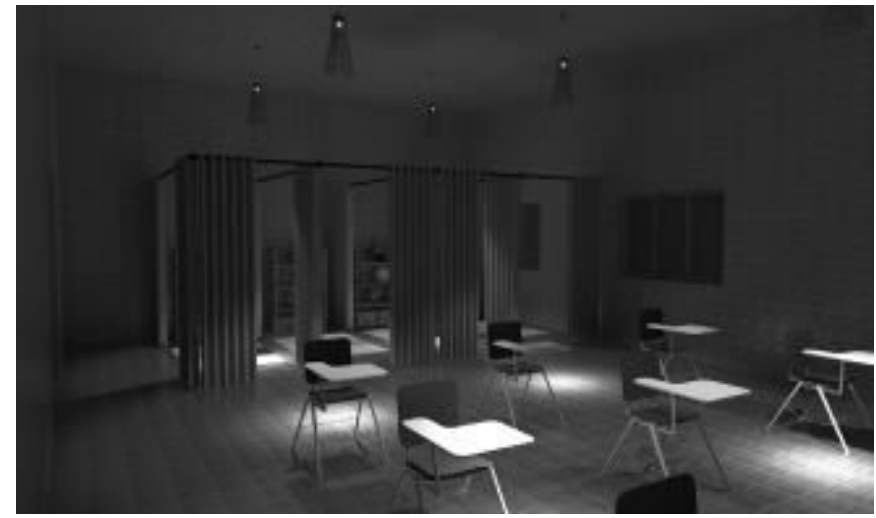

Gambar 6. Ruang intim.

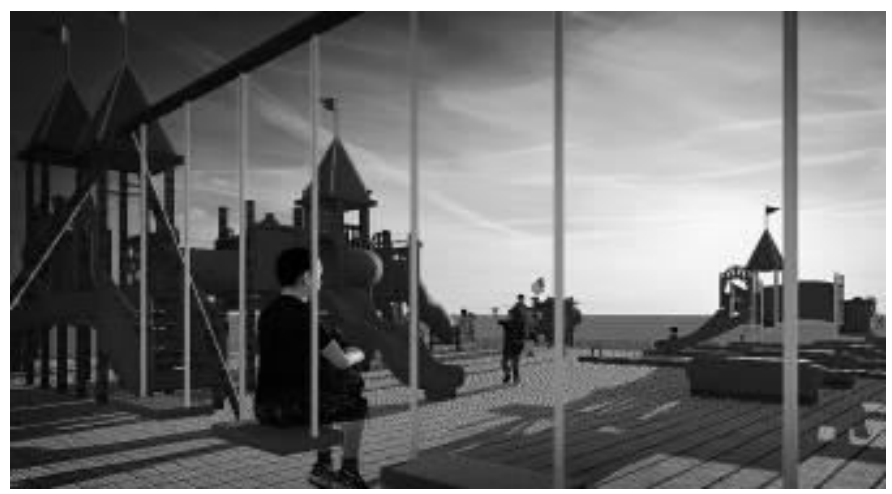

Gambar 7. Lahan bermain anak.

mengorientasikan diri secara tepat dalam matriks spasial (Gambar 5). Pada objek rancang ini salah satu metodanya dengan menggunakan persepsi ruang sebab subjek pengidap autis sangat peka terhadap bentuk, warna, garis karena jika tidak memerhatikan hal tersebut maka subjeknya akan merasa terganggu dan melakukan hal yang tidak diinginkan.

A large number of people have been surveyed recently regarding their wishes for a private, among people not institutions, a steadily higher number preferred single rooms through old age [5]. Ruang pribadi cukup penting pada objek rancang ini karena subjek pengidap autis menginginkan untuk menyendiri agar dapat mewujudkan keinginannya dengan rasa nyaman menurut subjeknya itu sendiri (Gambar 6). The absence of single rooms in all but the most expensive mental hospitals at least partly reflects the conclusion that mental patients do not have the same needs as others [5]. Tolak ukur subjek pengidap autis memerlukan keperluan yang berbedabeda menurut subjek tersebut. Sehingga ruang pribadi akan membeda-bedakan keperluan tiap individunya agar keperluannya dapat tercukupi.

A pioneer characterization of social space was made by Humphrey Osmond in his concept of sociopetal versus sociofugal. Sociopetal space is an area whose encourages social interaction, whereas its opposite, sociofugal space, separates or isolates people [5]. Ruang sosial ini cukup penting pada objek rancang ini, adanya ruang sosial akan meningkatkan komunikasi subjek pengidap autis untuk melatih agar dapat berkomunikasi dengan masyarakat atau individu satu dengan individu lainnya sehingga ruang sosial ini dapat menjadi alternatif untuk mengenalkan individu satu dengan individu lainnya (Gambar 7). 


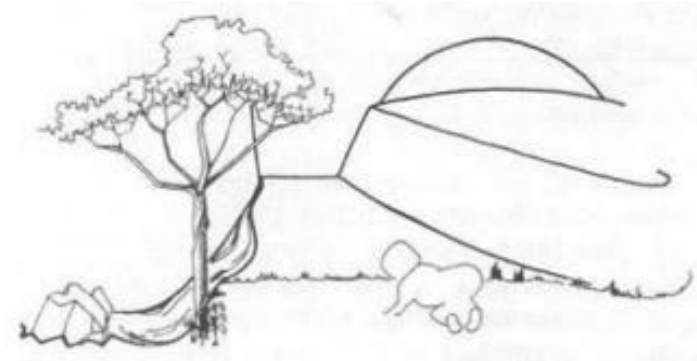

Gambar 8. Penggambaran mental image.

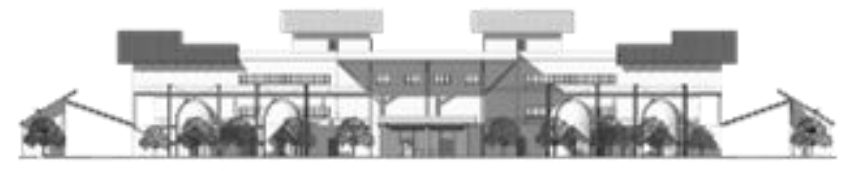

Gambar 9. Tampak utara.

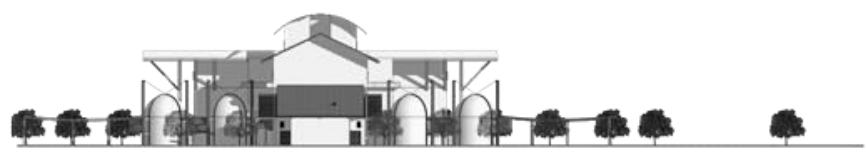

Gambar 10. Tampak timur.

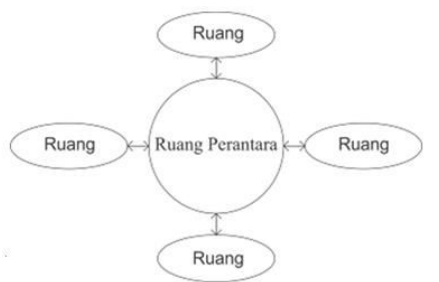

Gambar 11. Penggambaran Cul de Sac.

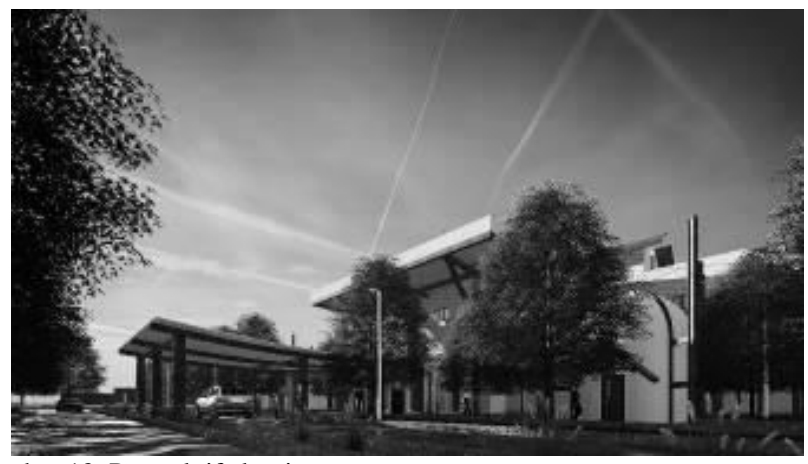

Gambar 12. Perspektif ekterior.

This gives the patient the possibility to control how and when they share spaces (acoustically as well as visually) [5]. Pada Social Space ini memerlukan desain yang menekankan pada kualitas akustik dan visual sehingga ketika individu satu dengan yang lain berinteraksi akan tersampaikan interaksi tersebut. Sehingga memerlukan material dan juga ukuran ruangan juga diperhatikan supaya kualitas akustik dan visual baik. Ruang terbuka juga baik untuk social space karena tidak ada Batasan pada ruang terbuka.

\section{B. Mental Image}

If architects are to discover how to design to fulfill or change the mental image which people have of desirable architecture, its is as important for them to understand how these images come into being as it is to recognize their pervasive role in behavior, in perception, and the symbolic

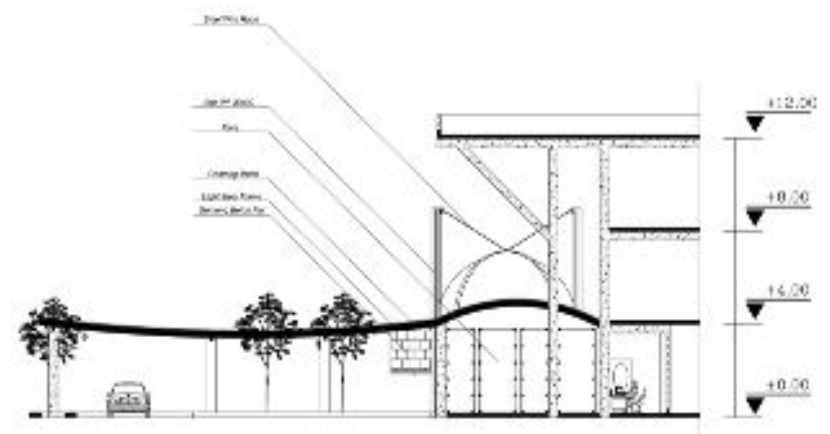

Gambar 13. Potongan lobby.

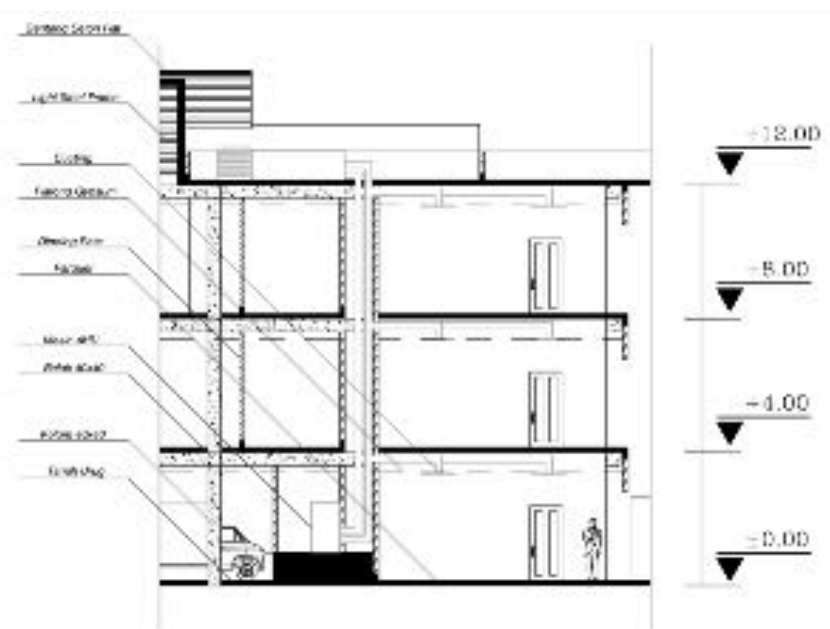

Gambar 14. Potongan sistem AHU.

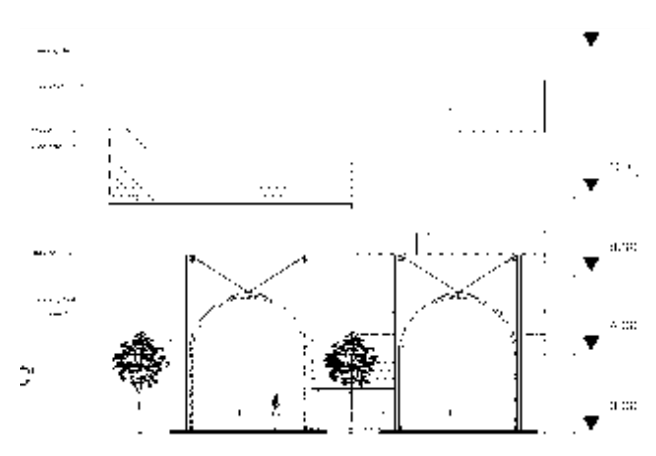

Gambar 15. Ruang diagnose.

processes [6]. Metode ini merupakan gambaran atau bisa juga disebut simbol untuk mempelajari hal yang belum pernah diketahui oleh subjeknya. Sehingga gambaran ini seperti menggambarkan suatu hal untuk memperkenalkan apa yang akan dihadapinya. Selain itu metode ini juga memperkenalkan kepada orang dalam mempersepsikan suatu hal (Gambar 8).

\section{HASIL DAN EKSPLORASI}

Objek rancang ini bertujuan untuk sebagai wadah memperbaiki perilaku anak penyandang autis yang berumur kurang lebih 5 tahun. Objek rancang ini dituntut mampu menjadi wadah bagi pengguna atau anak pengidap autis menurut hipersensitif dan hiposensitif tersebut. Sehingga tiap ruang didesain menurut dari kebutuhan anak pengidap autis dengan kriteria anak tersebut. Sehingga konsep pada objek 


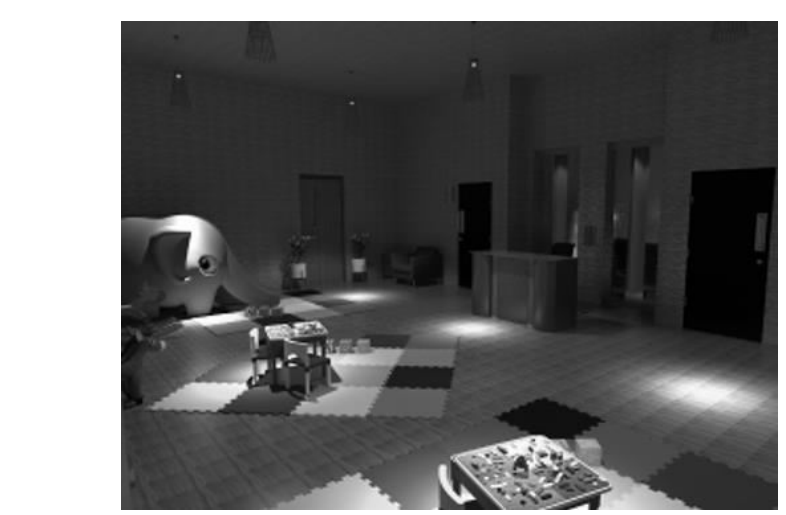

Gambar 16. Ruang transisi.

rancang ini berdasarkan kebutuhan dan mencegah dampak yang akan timbul pada pengguna objek rancang ini. Dan mengenalkan bagaimana dunia luar tersebut karena anak pengidap autis cenderung menyendiri, tidak mau keluar dari zona nyamannya. Menurut konsep diatas mendapatkan kriteria ruang menurut penggunanya sehingga karakteristik penggunanya perlu digali lebih dalam supaya pengguna dapat nyaman untuk menempati ruangan tersebut.

1. Konsep Bentuk

Anak autis adalah anak yang visual learner, dimana anak menyukai suatu bentuk yang menarik, teratur (Gambar 9) dan pastinya tidak membuatnya terdistraksi. Sehingga harus dipilih suatu bentuk massa yang disukai anak dan tentunya nanti bentuk tersebut dapat menampung segala penyimpangan perilaku anak. Bentuk yang disukai anak adalah bentuk-bentuk geometris, lingkaran dan lengkung dengan pengolahan yang mengandung unsur keteraturan dan kejelasan (Gambar 10).

2. Konsep Sirkulasi

Anak autis lebih menyukai suatu kejelasan, maka pola sirkulasi yang digunakan adalah pola sirkulasi langsung atau cul de sac. Pola sirkulasi ini mengarah langsung ke suatu tempat masuk, melalui sebuah jalan lurus yang segaris dengan alur sumbu bangunan. Tujuan visual yang mengakhiri pencapaian ini jelas sehingga anak mudah meramalkan tempat dimana ia berada. Bentuk ruang yang efektif dalam mendukung terjadinya interaksi di bangunan tersebut adalah gabungan bentuk organisasi ruang terpusat dan radial serta memiliki hubungan keterkaitan. Sehingga ruang terpusat adalah ruang perantara yang dapat menimbulkan interaksi antar individu ketika mereka ingin berpindah kelas atau tempat (Gambar 11).

\section{Konsep Ruang Luar}

Ruang luar adalah sebuah ruang yang terbentuk oleh batas horizontal bawah (bentang alam) dan batas vertical (massa bangunan atau vegetasi), ruang yang terjadi dengan membatasi alam, dengan memberi kerangka atau bingkai disebut juga arsitektur tanpa atap (Gambar 12). Penataan ruang luar yang disukai anak autis adalah adanya penataan yang teratur dan jelas. Penataan ruang luar selain tata taman juga mencakup penataan area bermain anak yang dapat melatif gerakan dan saraf sensorik.

\section{Konsep Sistem Struktur}

Sistem Struktur pada bangunan ini menggunakan portal. Karena beberapa ruangan menimbulkan beban berat dan harus ditopang dengan bentang yang lebar, kolom menggunakan beton sehingga dapat menopang keperluan diatas dan ada beberapa ruangan yang menggunakan baja WF karena adanya keperluan yang diperlukan anak autis pada ruangan tersebut (Gambar 13).

\section{Konsep Utilitas}

Bangunan ini merupakan bangunan yang menampung individu dengan karakteristik berbeda sehingga pengaturan penghawaan tiap ruang harus sama. Maka bangunan ini menggunakan AC central yang diatur melalui sistem AHU yang disediakan pada ruangan ini supaya individu yang berada diruangan ini merasakan kenyamanan sehingga tidak berperilaku yang menyimpang ketika individu tidak nyaman. Dan ruangan yang berdiri sendiri memakai AC split untuk keperluan tiap ruang yang tidak menyatu dengan bangunan pusat (Gambar 14).

\section{Konsep Teknis Dinding}

Dinding bangunan pada dasarnya menggunakan bahan yang sama yaitu dinding bata. Tetapi finishing dari dinding bata tersebut menggunakan cat dinding berwarna putih kehijauan agar ruangan berkesan lega meskipun terdapat barang yang banyak terisi. Sama sekali tidak menggunakan pola-pola pada dinding sehingga terkesan formal. Warna hijau juga menimbulkan perasaan nyaman, relaksasi, dan kesehatan emosi dan keuntungan menggunakan dinding bata mudah dibersihkan, tidak beracun, tidak menimbulkan api sehingga sesuai penanganan pengembangan terhadap anak autis yang rentan terhadap penyakit (Gambar 15).

\section{Konsep Teknis Teknis Plafon}

Plafon menggunakan warna yang sama dengan dinding dan tidak menggunakan ornament yang berlebihan sehingga ruangan terasa lega meskipun ketinggian plafon tidak terlalu tinggi (Gambar 15).

\section{Konsep Teknis Lantai}

Lantai tidak boleh licin karena dapat menimbulkan cedera pada autis sehingga lantai memakai bahan yang kasar tetapi dengan tekstur yang lunak. Hal ini perlu diperhatikan supaya anak autis terasa nyaman sehingga bahan yang cocok untuk ruangan anak autis yaitu karpet ataupun matras sebagai pelindung (Gambar 16).

\section{Konsep Aspek Keselamatan}

Kolom yang terdapat didalam ruangan tertentu harus menggunakan kolom tanpa sudut. Hal ini untuk menghindari anak melukai dirinya sendiri di sudut tajam pada kolom sehingga kolom ditonjolkan ke luar ruangan atau kolong mengikuti lebar dinding supaya tidak terlihat. Konsep pada objek rancang ini berdasarkan kebutuhan dan mencegah dampak yang akan timbul pada pengguna objek rancang ini. Dan mengenalkan bagaimana dunia luar tersebut karena anak pengidap autis cenderung menyendiri, tidak mau keluar dari zona nyamannya. Sehingga hal pertama yang dilakukan yaitu mengklasifikasi gangguan yang ada pada sekitar bangunan karena konsep dari bangunan ini bergantung pada human behavior maka kecenderungan membangun ditentukan terlebih dahulu.

Children with autism spectrum disorder have been observed to over respond to some stimuli and under respond to other sensory stimuli (e.g., to sound and pain). Pusat rehabilitasi 
anak autis ditempatkan terpusat supaya menghindari kebisingan dari seluruh sisi bangunan dan guna bangunan sekitar juga untuk mengurangi tingkat kebisingan dengan memakai solid walls pada bangunan sekitar. Bangunan sekitar mempresepsikan sebagai rumah-rumah kecil dan sebagai penangkap angin agar dapat masuk dan disalurkan ke pusat tatanan massa sehingga sirkulasi udara sangat terkontrol.

\section{KESIMPULAN}

Untuk mewujudkan ketercapaian untuk fasilitas terapi dalam arsitektur dapat dilakukan dengan menggunakan pendekatan human behavior dimana melihat langsung dampak dari anak autis tersebut kegemarannya dan ketidak sukaannya terhadap klasifikasikan untuk pencegahan pada anak autis yang berada di dalam bangunan tersebut.

Perancangan ini diperlukan analisa ruang berdasarkan preseden-preseden yang sudah ada. Analisa ruang tersebut dibutuhkan untuk mengetahui ruang apa saja yang akan dihadirkan pada bangunan ini sehingga dapat memenuhi kriteria yang sudah disepakati. Penempatan ruang menyesuaikan kebutuhan anak autis tersebut. Agar layanan terapi dapat berjalan semaksimal mungkin dan juga ruangruang didesain untuk anak autis melakukan kegiatan disana sehingga bentuk ruang tidak sama dengan ruangan anak-anak pada umumnya.

\section{DAFTAR PUSTAKA}

[1] T. Peeters, Autisme Hubungan Pengetahuan Teoritis Dan Intervensi Pendidikan Bagi Penyandang Autis. Jakarta: Dian Rakyat, 2004.

[2] Pemerintah Kota Surabaya Badan Perencanaan Pembangunan Kota Surabaya, "Rencana Detail Tata Ruang Kota Unit Pengembangan Wiyung. Pemerintah Kota Surabaya," 2009.

[3] J. Lang, Designing for Human Behavior: Architecture and the Behavioral Sciences. Pennsylvania: Ross, Inc, 1974.

[4] S. Gideon, Mechanization Takes Command: A Contribution to Anonymous History. New York: Oxford University Press, 1948.

[5] B. Sadock, Kaplan \& Sadock's Synopsis of Psychiatry: Behavioral Sciences / Clinical Psychiatry, 11th ed. New York, 2007.

[6] W. J. Cavanaugh, Architectural Acoustic: Principles and Practice. New York: John Wiley \& Sons Inc, 1999. 